\title{
Vaginal microbiome in women from Greenland assessed by microscopy and quantitative PCR
}

\author{
Raluca Datcu ${ }^{1}$, Dionne Gesink ${ }^{2}$, Gert Mulvad ${ }^{3}$, Ruth Montgomery-Andersen ${ }^{4}$, Elisabeth Rink ${ }^{5}$, Anders Koch ${ }^{6}$, \\ Peter Ahrens ${ }^{1}$ and Jørgen Skov Jensen ${ }^{1^{*}}$
}

\begin{abstract}
Background: Bacterial vaginosis (BV) is a common condition, although its aetiology remains unexplained. The aim of this study was to analyse the composition of vaginal microbiota in women from Greenland to provide a quantitative description and improve the understanding of BV.

Methods: Self-collected vaginal smears and swabs were obtained from 177 women. The vaginal smears were graded for BV according to Nugent's criteria. The vaginal swab samples were analysed by 19 quantitative PCRs (qPCRs) for selected vaginal bacteria and by PCR for four sexually transmitted infections (STIs).
\end{abstract}

Results: STIs were common: Mycoplasma genitalium 12\%, Chlamydia trachomatis 7\%, Neisseria gonorrhoeae 1\%, and Trichomonas vaginalis $0.5 \%$. BV was found in $45 \%$ of women, but was not associated with individual STIs. Seven of the 19 vaginal bacteria (Atopobium vaginae, Prevotella spp., Gardnerella vaginalis, BVAB2, Eggerthella-like bacterium, Leptotrichia amnionii, and Megasphaera type 1) had areas under the receiver operating characteristic (ROC) curve > 85\%, suggesting they are good predictors of BV according to Nugent. Prevotella spp. had the highest odds ratio for BV (OR 437; 95\% Cl 82-2779) in univariate analysis considering only specimens with a bacterial load above the threshold determined by ROC curve analysis as positive, as well as the highest adjusted odds ratio in multivariate logistic regression analysis (OR 4.4; $95 \% \mathrm{Cl}$ 1.4-13.5). BV could be subdivided into clusters dominated by a single or a few species together.

Conclusions: BV by Nugent score was highly prevalent. Two of seven key species (Prevotella spp. and A. vaginae) remained significantly associated with BV in a multivariate model after adjusting for other bacterial species. G. vaginalis and Prevotella spp. defined the majority of BV clusters.

Keywords: Bacterial vaginosis, Nugent criteria, Sensitivity, Specificity, ROC curve analysis, Clusters

\section{Background}

The human vaginal flora has an impact on the health of a woman and, if she is pregnant, on her foetus and newborn child. It is generally accepted that a healthy vaginal microbiome is dominated by Lactobacillus spp., while the replacement of these bacteria with facultative and strict anaerobes, such as Gardnerella vaginalis, Prevotella spp., Peptostreptoccocus spp., Mobiluncus spp., and a wide range of fastidious and uncultured bacteria leads to a switch from normal vaginal microbiota to bacterial vaginosis (BV) [1].

\footnotetext{
* Correspondence: jsj@ssi.dk

${ }^{1}$ Microbiology and Infection Control, STI, Research and Development, Statens Serum Institut, Artillerivej 5, DK 2300 Copenhagen S, Denmark

Full list of author information is available at the end of the article
}

BV is the predominant cause of genital complaints in women of childbearing age worldwide [2]. About one in five adult women will have a BV episode annually; however, the condition is symptomatic in only half of women with $\mathrm{BV} . \mathrm{BV}$ is associated with preterm birth and an increased risk of spontaneous miscarriage, increased risk of acquiring sexually transmitted infections (STIs), particularly genital herpes and HIV, as well as with post-abortion endometritis and post-hysterectomy vaginal cuff infection [1].

BV is commonly diagnosed clinically using Amsel's criteria [3], which consist of four characteristics, including a homogeneous, white vaginal discharge; fishy odour of the vaginal discharge before or after addition of $10 \%$ potassium hydroxide; a $\mathrm{pH}$ of the vaginal fluid higher than 4.5 ; and the presence of clue-cells (squamous epithelial

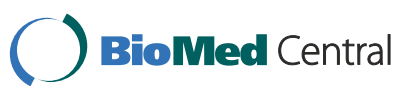


cells covered with adherent bacteria). At least three of the criteria must be present to diagnose BV. In research settings, a BV diagnosis is usually determined by microscopy of Gram-stained vaginal secretions, and the Nugent score is considered the gold standard [4]. More recently, an alternative scoring of vaginal smears, the Claeys' criteria, was described [5], aiming to improve the discrimination between various morphotypes not accounted for in the Nugent score. The Claeys score is based on Ison-Hay's criteria [6] with a more detailed evaluation of normal flora. Using the Claeys score, pregnant women with BV-like flora (grade 2 or 3), grade 1-like (small, short, irregularly shaped Gram positive rods) or 1-PMN (smears with over 50 polymorphonuclear leukocytes [PMN]/high power microscopy field in the absence of Candida) were shown to be at high risk for adverse pregnancy outcomes [7].

Despite significant research efforts in this area, no aetiological factors for BV have been identified [8]. Striking differences among populations have been observed; e.g., black women have significantly higher rates of BV than Caucasian women [9], and vaginal $\mathrm{pH}$ varies among different ethnic groups: Hispanic and black women have a higher average vaginal $\mathrm{pH}$ compared to Asians and Caucasians [10]. On the other hand, it has been suggested that a high Nugent score in asymptomatic women should be considered a separate group of normal flora (community group IV) [10]. Thus, the vaginal microbiota appears to depend partly on the ethnicity of the host and, consequently, of genetic and/or geographic and social factors.

It has been debated whether BV is sexually transmitted, as the carriage rates of G. vaginalis, a key bacterium in BV [11], were significantly higher in heterosexual men than among men who have sex with men [12], and BV was not found in sexually inexperienced women [13]. Many epidemiological features of BV are the same as those of STIs [14], although treatment of the male sexual partner does not decrease the rate of BV recurrence. However, BV may be considered a sexually enhanced disease, with the frequency of unprotected intercourse being a major predisposing factor [15].

Although the prevalence of STIs is high in the Greenlandic population [16,17], there are few publications describing the vaginal microbiota of women from Greenland. One study found a BV prevalence of $38 \%$ in Nuuk using Amsel's criteria [18].

Microscopy of Gram-stained vaginal smears is considered the gold standard for diagnosing BV, but this approach does not provide detailed information about the vaginal microbiome, whereas species-specific real-time PCR can identify and quantify each bacterium. In this work, we present a cross-sectional, observational study on a cohort of women from Greenland aimed at presenting a detailed quantitative characterisation of the vaginal bacteria composition using microscopy and 19 quantitative real-time PCRs specific for bacteria that have been commonly reported as part of the human vaginal microbiome. We used threshold quantification to optimise the molecular techniques by using receiver operating characteristic (ROC) curve analysis to objectively define cut-off points for the diagnostic tests. We refer to this approach as quantitative detection, in which samples above the cut-off are considered positive, while samples with a bacterial load below the threshold are scored as negative. In qualitative detection, the samples are considered positive if DNA is detected (presence vs. absence). The diagnostic performance for BV detection was evaluated by both qualitative and quantitative detection using Nugent's score as the reference.

\section{Methods}

\section{Study population and specimens}

A total of 196 women were included in "Inuulluataarneq" (the Greenland Sexual Health Project), a project aimed at quantifying the prevalence of STIs in Greenland and to identify individual, familial, social, cultural and environmental factors contributing to Greenland's high STI rates $[19,20]$. The two inclusion periods were from July to October 2008 in Nuuk and November 2009 in Sisimiut during "Health Week." Women were recruited from the general population via the population registry and by direct contact via telephone calls and advertising in local media, as previously described [17].

\section{Ethics statement}

The project was approved by the Greenlandic ethics board, under the auspices of the Commission for Research in Greenland (KVUG), and the University of Toronto Research Ethics Board (21108 and 22173, September 2007 and June/October 2009, respectively). Study subjects provided written informed consent before participating in the study.

\section{Sample collection}

Self-obtained vaginal swabs, vaginal smears, and firstvoid urine specimens were collected after an intervieweradministered structured survey. The women were given a pictorial instruction sheet on how to self-collect vaginal swabs by inserting a flocked swab (Copan, Brescia, Italy) approximately five $\mathrm{cm}$ into the vagina, using the breaking score as a guide to ensure that samples were collected properly. One swab was rolled onto a pre-labelled slide, which was left to air-dry. A second flocked swab was similarly obtained and placed in UTM transport medium (Universal Transport Medium, Copan, Brescia, Italy). Firstvoid urine was collected in GeneLock nucleic acid stabilisation medium (Sierra Molecular Corp., Sonora, CA, USA). The samples were stored in a refrigerator at $5^{\circ} \mathrm{C}$ until they were shipped at weekly intervals from Nuuk at ambient 
temperature and from Sisimiut in one bulk shipment at the end of Health Week to Statens Serum Institut in Denmark.

\section{Microscopy}

BV was diagnosed by microscopy of Gram-stained smears and classified by Nugent score [4]. All slides were scored by the same investigator (RD), who was blinded to any clinical or laboratory results.

Inflammation was graded in at least 5 microscopic fields as 0 (no PMN) $+(<10 \mathrm{PMN} /$ high power field [hpf]), ++ (10-50 PMN/hpf), or +++ ( $>50 \mathrm{PMN} / \mathrm{hpf})$. A PMN count $>10 /$ hpf (i.e., ++ and +++ ) was considered abnormal [7]. The presence of Candida cells and hyphae was graded as: absence, few cells/hyphae $(\leq 3$ on average in at least $10 \mathrm{hpf}$ ) and many cells/hyphae ( $>3$ on average/hpf).

\section{DNA extraction and positive controls for PCR assays}

Cells were released from vaginal swab specimens in UTM by thorough vortexing. Cells from $950 \mu \mathrm{l}$ of the UTM were pelleted by centrifugation for 15 minutes at $30,000 \times g$. The supernatant was removed, and the pellet was vortexed for 60 seconds with $150 \mu \mathrm{l}$ of $20 \%$ Chelex 100 slurry (BioRad, Hercules, CA, USA) in TE buffer (10 mM Tris- $\mathrm{HCl}[\mathrm{pH} 8.0]$ and $1 \mathrm{mM}$ EDTA). The samples were heated at $95^{\circ} \mathrm{C}$ for 10 minutes, and condensation droplets were collected by a brief centrifugation [21]. Urine specimens were treated similarly.

Positive controls and specificity controls for the PCRs were obtained by DNA extraction from culture collection strains of Atopobium vaginae (CCUG $38953^{\mathrm{T}}$ ), Sneathia sanguinegenes (CCUG $41628^{\mathrm{T}}$ ), Leptotrichia amnionii (DSM 16630), Mobiluncus curtisii (CCUG $21018^{\mathrm{T}}$ ), M. mulieris (CCUG 20071 ${ }^{\mathrm{T}}$ ), Lactobacillus iners (CCUG $28746^{\mathrm{T}}$ ), L. crispatus (CCUG 30722), L. gasseri (DSM 14869), L. jensenii (CCUG 21961), Gardnerella vaginalis (ATCC $3717^{\mathrm{T}}$ ), Mycoplasma hominis (ATCC 15488), Ureaplasma parvum (ATCC $27815^{\mathrm{T}}$ ), U. urealyticum (ATCC $27618^{\mathrm{T}}$ ), Finegoldia magna (DSM 20470 ${ }^{\mathrm{T}}$ ), Peptostreptococcus anaerobius (CCUG 7835), and Veillonella montpellierensis (CCUG 48299), and from clinical isolates of Prevotella oris, P. bivia (2 different strains), P. nigrescens (2 different strains), P. buccae (2 different strains), $P$. loeschii, and $P$. intermedia identified by biochemical properties and MALDI-TOF and/or sequencing of $16 \mathrm{~S}$ rRNA genes. DNA from cultured bacteria was extracted using the standard protocol with the QIAGEN Blood and Tissue kit (Qiagen, Hilden, Germany) except for Lactobacillus spp., for which the cells were suspended in $400 \mu \mathrm{l}$ lysis buffer $(20 \mathrm{mM}$ Tris-HCl; $2 \mathrm{mM}$ EDTA; $1.2 \% \mathrm{vol} / \mathrm{vol}$ Triton X-100) as previously published [22], $6 \mathrm{mg}$ of lysozyme dissolved in $15 \mu \mathrm{l}$ TE buffer was added and samples were incubated for 30 minutes at $37^{\circ} \mathrm{C}$.
Subsequently, the standard QIAamp DNA mini kit protocol was followed.

For uncultured bacteria BVAB 1, 2, 3, TM7, Megasphaera type 1 and 2, and Eggerthella-like bacterium, PCR products from a positive clinical sample were used as positive controls. The PCR products were gel-purified with a QIAquick Gel Extraction Kit (Qiagen) and DNA sequenced for verification.

Genomic and amplified DNA for positive controls were quantified fluorometrically with a Qubit fluorometer, using Quant-i $\mathrm{T}^{\mathrm{m}} \mathrm{dsDNA}$ HS Assay Kit (Life Technologies Corp., Paisly, UK). Standard curves for quantitative PCRs were generated using 10-fold dilutions ranging from 1 genome equivalent (geq) $/ \mu$ lo $10^{7}$ geq $/ \mu$ l in TE buffer containing $1 \mu \mathrm{g} / \mathrm{ml}$ of calf thymus DNA (D-8661; Sigma-Aldrich).

\section{PCR analyses}

Vaginal swabs and FVU were examined by PCR for Mycoplasma genitalium, Chlamydia trachomatis, Neisseria gonorrhoeae, and Trichomonas vaginalis as previously described [17]. M. genitalium was detected by real-time PCR targeting the MgPa-gene [21] and confirmed by conventional PCR for the 16S rRNA gene [23]. C. trachomatis was detected by real-time PCR targeting the 16S rRNA gene [24] and all positive results were confirmed by realtime PCR for the C. trachomatis cryptic plasmid [24]. There was no evidence that the new variant of $C$. trachomatis was present in these samples [17]. N. gonorrhoeae was detected by a porA pseudogene real-time PCR [25]. T. vaginalis was detected by a conventional PCR with primers targeting a $T$. vaginalis specific repeat DNA fragment [26].

Quantitative PCRs were performed on vaginal swabs for selected BV associated bacteria, including A. vaginae, S. sanguinegens, L. amnionii, Bacterial VaginosisAssociated Bacterium 1, 2, 3 and TM7 (BVAB 1, 2, 3 and TM7), Megasphaera type 1 and 2, Eggerthella-like bacterium, M. curtisii and M. mulieris, L. iners, G. vaginalis, $M$. hominis, $U$. parvum, $U$. urealyticum, $F$. magna, and Prevotella spp. Primers used for Megasphaera type 1 and Eggerthella-like bacterium as well as primers and probe for G. vaginalis were previously published by Fredricks $[27,28]$, and specificity was documented by amplicon sequencing. For the remaining assays, specificity was documented by melt-curve analysis and during assay optimisation by gel-electrophoresis that demonstrated amplicons of the expected length. Sequencing (Big-Dye version 3.0, Life Technologies) of selected amplicons was used to document specificity.

PCR with TaqMan probes (A. vaginae, S. sanguinegens, $L$. amnionii, $L$. iners, $M$. hominis) was performed in a $50 \mu \mathrm{l}$ final volume containing $1 \times$ PCR Reaction Buffer $20 \mathrm{mM}$ Tris- $\mathrm{HCl} \mathrm{pH} \mathrm{8.4,} 50 \mathrm{mM} \mathrm{KCl} \mathrm{-} \mathrm{(Life} \mathrm{Tech-}$ nologies); $125 \mu \mathrm{M}$ (each) of dATP, dCTP and dGTP; 
and $250 \mu \mathrm{M}$ dUTP; $1 \mu \mathrm{M}$ forward and reverse primers, $75 \mathrm{nM}$ probe, $5 \mathrm{mM} \mathrm{MgCl}_{2}$, and $2 \mathrm{U}$ Platinum $^{\odot}$ Taq DNA polymerase (Life Technologies). For the G. vaginalis TaqMan probe assay, Platinum ${ }^{\circledR}$ Quantitative PCR SuperMix-UDG (Life Technologies) and the same final concentrations of primers, probe and $\mathrm{MgCl}_{2}$ as above were used. $U$. urealyticum and $U$. parvum were detected in a multiplex PCR with $150 \mathrm{nM}$ probes, $1 \mu \mathrm{M}$ of the common forward primer and $2 \mu \mathrm{M}$ of reverse primer for $U$. urealyticum and $1 \mu \mathrm{M}$ of reverse primer for $U$. parvum; the other reagents were as previously described. An ABI 7500 Sequence Detection System was used with 96-well conventional blocks (Life Technologies) with a $95^{\circ} \mathrm{C}$, $10 \mathrm{~min}$ initial denaturation and 50 cycles of $95^{\circ} \mathrm{C}$ for $15 \mathrm{~s}$ for denaturation and $60^{\circ} \mathrm{C}$ for $1 \mathrm{~min}$ for annealing and extension.

SYBR Green assays (BVAB1, BVAB2, BVAB3, BVABTM7, Megasphaera type 1 and 2, Eggerthella-like bacterium, M. curtisii, M. mulieris, Prevotella spp., and F. magna) were performed in a $50 \mu \mathrm{l}$ final volume with reagents as described for TaqMan assays, except that the primers were used at $0.4 \mu \mathrm{M}$ and $\mathrm{MgCl}_{2}$ concentrations varied between 1.5-3.5 mM, as listed in Additional file 1: Table S1. SYBR Green (Life Technologies) was used at a 1:5000 dilution. An ABI 7500 instrument was used with cycling conditions consisting of an initial $10 \mathrm{~min}$ denaturation followed by 10 cycles of touch-down PCR with a $1^{\circ} \mathrm{C}$ decrement per cycle until reaching the intended annealing temperature, which was used for the subsequent 30 cycles followed by a melt-curve analysis. Cycling conditions for each of the bacterial species are listed in Additional file 1: Table S1.

All results are expressed as the number of $16 \mathrm{~S}$ rRNA gene copies/ml UTM.

All vaginal swab samples were checked for inhibition in the diagnostic PCRs detecting STI pathogens. However, to estimate the robustness and influence of nontarget DNA on the SYBR Green assays (BVAB1, 2, 3, TM7, Eggerthella-like bacterium, Megasphaera type 1 and 2, M. curtisii, M. mulieris), the standard curves were evaluated with and without the presence of negative clinical samples.

\section{PCR method validation}

Primers for A. vaginae, L. amnionii, S. sanguinegens, and $F$. magna were designed for the present study. The specificity of the primer sequences was examined by BLAST search of GenBank sequences. The TaqMan assays were challenged with $10^{5}$ genome equivalents (geq) of A. vaginae, L. amnionii, and S. sanguinegens. For the F. magna PCR, seven amplicons from random clinical specimens were sequenced and had 100\% homology to the GenBank sequence; furthermore, purified DNA from the related species Peptostreptococcus anaerobius and Veillonella montpellierensis did not crossreact in the assay.

For BVAB1, BVAB2, Megasphaera type 2, BVAB TM7, $M$. curtisii, and M. mulieris, the published primers were slightly modified at the $5^{\prime}$-end to adjust the annealing temperature (see Additional file 1: Table S1). However, the 3 '-end remained unchanged, and therefore the specificities of the primers as described in the original publications were preserved [27,28].

For BVAB3, a combination of forward and reverse primers published in two different studies were used and modified at the $5^{\prime}$-end (see Additional file 1: Table S1). A BLAST search showed a 100\% match with the BVAB3 $16 \mathrm{~S}$ rRNA gene sequence and lacked any other significant matches. The sequencing of amplicons from a random clinical specimen revealed a $100 \%$ match with the published sequence, and the melt-curve analysis showed distinct peaks.

M. curtisii DNA did not cross react in the $M$. mulieris real-time assay and vice-versa.

For the L. iners assay, the forward and reverse primers were combined from assays described in two previous publications [22,29], modified at the $5^{\prime}$-end (see Additional file 1: Table S1) and used with a probe designed for the present study. Cross-reactions with L. crispatus, L. gasseri, and $L$. jensenii DNA were studied by challenging the assays with $10^{5}$ geq of each species.

The Prevotella spp. primers were previously published and slightly modified at the $5^{\prime}$-end (see Additional file 1 : Table S1). The PCR primers were genus-wide and, according to a BLAST search, matched perfectly to 20 different Prevotella species: P. timonensis, P. bivia, P. melaninogenica, $P$. buccae, $P$. histicola, $P$. disiens, P. buccalis, P. scopos, P. fusca, P. copri, P. salivae, P. oris, P. veroralis, $P$. paludivivens, $P$. pallens, $P$. oulorum, $P$. nigrescens, P. maculosa, P. corporis, and P. intermedia. Dilutions ranging from 1 geq $/ 5 \mu \mathrm{l}$ to $10^{4}$ geq $/ 5 \mu$ l were prepared from clinical isolates of $P$. oris, $P$. bivia (2 different strains), $P$. nigrescens (2 different strains), $P$. buccae (2 different strains), $P$. loeschii, and $P$. intermedia strains and used as templates in the Prevotella spp. assay to determine sensitivity for different strains.

\section{Precautions to avoid PCR product carryover}

All pre-PCR manipulations were performed in a laboratory accredited according to the ISO 17025 standard to perform diagnostic PCR. Strict physical separation between PCR setup and analysis laboratories was maintained, and separate staff were dedicated to pre- and post-PCR work. All pre-PCR steps were carried out in laminar flow hoods, and sterile filter tips were used in all sample manipulations. All surfaces in the PCR setup laboratory were exposed to UV light between sessions and regularly wiped with a solution containing hypochlorite to destroy contaminating 
DNA [30]. At least two negative controls, including a mock-extracted sample, were included in each PCR run. All PCRs were performed with dUTP instead of dTTP to allow enzymatic prevention of PCR product carryover with uracil- $N$-glycosylase. Uracil- $N$-glycosylase was not used, however, because no carryover was observed.

\section{Determination of cut-off for optimal BV prediction}

ROC curve analysis was used to determine the optimal bacterial load threshold in geq/ml UTM in women with and without BV, weighing sensitivity and specificity equally. For the calculation of the sensitivity and specificity for BV prediction, the Nugent score was used as the gold standard, and Grade II (intermediate flora) was excluded from the evaluation. For all 19 bacterial species, the sensitivity and specificity before ROC (qualitative detection) was calculated for 79 participants with BV and 73 participants without BV. Bacterial species with an area under the curve $(\mathrm{AUC})>85 \%$, a value that suggested good discriminatory power, were selected for further analysis in a multivariate logistic regression model.

\section{Statistical methods}

ROC curve analysis, Fisher's exact test, and odd-ratios with confidence intervals as well as kappa statistics were calculated in StatsDirect version 2.7.8 (StatsDirect Ltd., Cheshire, UK).

Logistic regression analysis and Cochran-Armitage trend tests were performed in SAS version 9.2 (SAS Institute Inc. Cary, NC, USA). A heat-map was constructed by normalising the number of $16 \mathrm{~S}$ rRNA gene copies $/ \mathrm{ml}$ UTM (the proportion of gene-copies for an individual species to the total sum of gene-copies for all bacteria studied) and using the Heat map routine in the $R$ program package version 2.15.0 (The R Foundation for Statistical Computing). Co-occurrence of bacterial taxa was investigated by calculating Spearman correlation coefficients using the routine correlation orders in the $\mathrm{R}$ program package. The significance level was 5\%, and two-sided results were used throughout.

\section{Results}

\section{Study population}

Out of a total of 196 women enrolled in "Inuulluataarneq," 177 women provided both swabs and suitable smears and were considered eligible. The women ranged from $15-$ 65 years in age, with a median of 24 and mean of 29 (Table 1). Six participants were between 55 and 65 years old and presumably post-menopausal, but no information regarding age of menopause was collected. The median lifetime number of male sexual partners was 12.5 , range $0-320$ and interquartile range 20 . Among the 168 women who provided information about their lifetime number of female sexual partners, 30 women had
Table 1 Study participants, characteristics and demographics

\begin{tabular}{ll}
\hline Age & \\
Range & $15-65$ years \\
Median (50th percentile) & 24 years \\
Lower quartile (25th percentile) & 19 \\
Upper quartile (75th percentile) & 37 \\
Inclusion town & $\mathbf{N}^{1}(\%)$ \\
Nuuk & $83(47 \%)$ \\
Sisimiut & $94(53 \%)$ \\
BV diagnosis by Nugent score & $\mathbf{N}(\%)$ \\
Grade I (normal) & $73(41 \%)$ \\
Grade II (intermediate) & $25(14 \%)$ \\
Grade III (BV) & $79(45 \%)$ \\
STls ${ }^{2}$ and yeast infection & $\mathbf{N}(\%)$ \\
Mycoplasma genitalium & $22(12 \%)$ \\
Chlamydia trachomatis & $12(7 \%)$ \\
Neisseria gonorrhoeae & $2(1 \%)$ \\
Trichomonas vaginalis & $1(0.5 \%)$ \\
Yeasts & \\
Lifetime number of male sexual partners &
\end{tabular}

${ }^{1} \mathrm{~N}$ indicates number of participants.

${ }^{2}$ Considered positive if specific PCR was found positive in swab, urine or both. ${ }^{3}$ Either spores, hyphae or both by microscopy.

${ }^{4}$ Only 168 women gave information.

female sexual partners, including 26 who had male partners as well. Twelve women were registered as having no history of male or female sex partners, of whom four were diagnosed with BV by Nugent's classification. The majority of the women $(72 \%, 117$ of 163 who answered the question) reported that they would always use a condom with a new partner they had only known for a few weeks. Participants were asked whether they had any STI symptoms and 67 (75\%) of the 89 women who answered this question declared that they had no symptoms, 15 women said they did not know and 7 women reported symptoms. Among the women who reported symptoms, two had STIs and four had BV. No questions were asked about contraceptive use, douching or recent antibiotic use. However, douching is known not to be a common practice in Greenland. 
As previously described [17], 22 women (12\%) were positive for $M$. genitalium, 12 (7\%) were positive for C. trachomatis, 2 (1\%) for $N$. gonorrhoeae and one woman had $T$. vaginalis $(0.5 \%)$ in either the vaginal swab sample or in the first void urine. Three women had a mixed infection with $M$. genitalium and C. trachomatis.

\section{PCR methods validation}

No cross-reactions were observed in the A. vaginae, L. amnionii or S. sanguinegens TaqMan assays when challenged with $10^{5}$ geq of the other species. Similarly, no cross reactions with L. crispatus, L. gasseri or L. jensenii DNA were observed in the $L$. iners assay.

The sensitivity of the Prevotella spp. assay for various species was determined to be 1 geq for $P$. oris, 10 geq and 100 geq for two strains of $P$. bivia, 10 geq for $P$. nigrescens (two strains), 1 geq for $P$. buccae (two strains), and 80 geq for $P$. intermedia. For P. loeschii, the sensitivity of the Prevotella spp. assay was much lower $\left(4 \times 10^{3}\right.$ geq), as there were several mismatches in the primer sequence.

The limit of detection for the real-time PCR assays is shown in Additional file 1: Table S1.

\section{BV microscopy results}

The BV prevalence was $45 \%$ as determined by Nugent's classification, and 73 participants (41\%) had a normal score, while 25 (14\%) had an intermediate score (Table 1). Most women (80\%) had normal leucocyte counts, i.e., below $10 \mathrm{PMN} / \mathrm{hpf}$, while 35 women (20\%) had more than $10 \mathrm{PMN} / \mathrm{hpf}$, suggesting inflammation. Among the women with high leucocyte counts, 11 (31\%) were positive for STIs, and 2 had vulvovaginal candidiasis. Fourteen women $(8 \%)$ carried yeasts, as determined by microscopy (Table 1).

\section{Determination of cut-off for optimal BV prediction}

Because the sensitivity and specificity of BV prediction by qualitative detection (presence versus absence) were quite low for all species (Table 2), ROC curve analysis was used to determine the optimal threshold for the bacterial load (cut-off) for BV prediction. The cut-off or threshold according to ROC curve analysis is shown for each species in Table 2. An area under the curve (AUC) of $>85 \%$, suggesting a good discriminatory power, was found for A. vaginae (97\%), Prevotella spp. (96\%), G. vaginalis (95\%), BVAB2 (94\%), Eggerthella-like bacterium (91\%),

Table 2 Sensitivity and specificity before (qualitative detection ${ }^{1}$ ) and after (quantitative detection ${ }^{2}$ ) applying ROC curve analysis

\begin{tabular}{|c|c|c|c|c|c|c|c|c|c|c|c|}
\hline \multirow[t]{2}{*}{ Species } & \multicolumn{4}{|c|}{ Qualitative detection $^{1}$} & \multicolumn{5}{|c|}{ Quantitative detection ${ }^{2}$} & \multicolumn{2}{|c|}{ AUC } \\
\hline & Se (\%) & $95 \% \mathrm{Cl}$ & Sp (\%) & $95 \% \mathrm{Cl}$ & Se (\%) & $95 \% \mathrm{Cl}$ & Sp (\%) & $95 \% \mathrm{Cl}$ & Cut-off/ml & Size (\%) & $95 \% \mathrm{Cl}$ \\
\hline Atopobium vaginae* & 100 & $95-100$ & 25 & $15-36$ & 95 & $88-99$ & 92 & $83-97$ & $\geq 55556$ & 97 & $95-99$ \\
\hline Sneathia sanguinegens & 75 & $64-84$ & 86 & 76- 93 & 67 & $56-77$ & 97 & $90-100$ & $\geq 14127$ & 85 & $79-90$ \\
\hline Leptotrichia amnionii* & 86 & $76-93$ & 59 & $47-70$ & 80 & $69-88$ & 97 & $90-100$ & $\geq 1746$ & 89 & 83-94 \\
\hline BVAB 1 & 67 & $56-77$ & 68 & $57-79$ & 54 & $43-66$ & 93 & $85-98$ & $\geq 9841$ & 75 & $68-82$ \\
\hline$B \vee A B 2^{*}$ & 91 & $83-96$ & 79 & $68-88$ & 87 & $78-94$ & 97 & $90-100$ & $\geq 3492$ & 94 & $90-98$ \\
\hline BVAB 3 & 66 & $54-76$ & 86 & $76-93$ & 66 & $54-76$ & 92 & $83-97$ & $\geq 95$ & 80 & $74-86$ \\
\hline BVAB-TM7 & 34 & $24-46$ & 100 & $95-100$ & 34 & $24-46$ & 100 & $95-100$ & $\geq 2698$ & 67 & $62-72$ \\
\hline Megasphaera type $1^{*}$ & 86 & $76-93$ & 59 & $47-70$ & 81 & $71-89$ & 99 & $93-100$ & $\geq 41111$ & 88 & $82-94$ \\
\hline Megasphaera type 2 & 32 & $22-43$ & 93 & $85-98$ & 28 & $18-39$ & 100 & $95-100$ & $\geq 1111$ & 63 & $58-69$ \\
\hline Eggerthella-like bacterium* & 95 & $88-99$ & 36 & $25-48$ & 78 & $68-87$ & 96 & $88-99$ & $\geq 297937$ & 91 & $86-96$ \\
\hline Mobiluncus curtisii & 25 & $16-36$ & 99 & $93-100$ & 25 & $16-36$ & 99 & $93-100$ & $\geq 794$ & 62 & $57-67$ \\
\hline Mobiluncus mulieris & 20 & $12-31$ & 93 & $85-98$ & 15 & $8-25$ & 99 & $93-100$ & $\geq 166349$ & 57 & $52-62$ \\
\hline Gardnerella vaginalis* & 100 & $95-100$ & 3 & $0.3-10$ & 87 & $78-94$ & 92 & $83-97$ & $\geq 4803175$ & 95 & $91-98$ \\
\hline Mycoplasma hominis & 63 & $52-74$ & 85 & $75-92$ & 58 & $47-69$ & 96 & $88-99$ & $\geq 3968$ & 78 & $71-84$ \\
\hline Ureaplasma parvum & 51 & $39-62$ & 49 & $37-61$ & 28 & $18-39$ & 75 & $64-85$ & $\geq 31746$ & 50 & $42-59$ \\
\hline Ureaplasma urealyticum & 18 & $10-28$ & 90 & $81-96$ & 14 & $7-24$ & 95 & $87-98$ & $\geq 22381$ & 54 & $49-59$ \\
\hline Finegoldia magna & 63 & $52-74$ & 59 & $47-70$ & 63 & $52-74$ & 59 & $47-70$ & $\geq 159$ & 61 & $52-69$ \\
\hline Prevotella spp.* & 97 & $91-100$ & 4 & $0.8-12$ & 95 & $88-99$ & 96 & $88-99$ & $\geq 888889$ & 96 & $92-100$ \\
\hline
\end{tabular}

${ }^{1}$ Presence versus absence as determined by qPCR.

${ }^{2}$ Presence ( $\geq$ cut-off $/ \mathrm{ml}$ ) versus absence (< cut-off $/ \mathrm{ml}$ ) with cut-off determined by ROC curve analysis.

A total of 79 participants with Nugent III and 73 with Nugent I were used for the evaluation. Intermediate flora not included. L. iners is excluded from the table because it acts as a negative predictor for BV.

*Bacterial species with area under the ROC curve (AUC) $>85 \%$. 
L. amnionii (89\%), and Megasphaera type 1 (88\%). The ROC curve for L. iners was concave because this bacterium was predictive for normal vaginal flora.

A. vaginae had the largest AUC (97\%), indicating the best diagnostic accuracy. A combination of $A$. vaginae and Prevotella spp. in quantitative detection had a specificity of $99 \%$ and sensitivity of $90 \%$, while A. vaginae or Prevotella spp. gave optimal sensitivity $(100 \%)$ but a specificity of $89 \%$.

\section{Relationship between PCR results and microscopy}

The average number of non-Lactobacillus species detected per participant was 11.7 (range 5-16) for women with BV, 6.2 (range 3-10) for women with a normal score, and 8.6 (range 4-15) for women with an intermediate score using qualitative data (presence versus absence) from the 18 specific assays. For each group, the difference in diversity was statistically significant compared to any other group.

The percentage of cases in which each qPCR assay was positive by Nugent score category is presented in Table 3. A significantly increasing trend in the proportion of positive results in qualitative detection was found with increasing BV grade for all non-Lactobacillus species except G. vaginalis, $U$. parvum, $U$. urealyticum, and Prevotella spp., while all non-Lactobacillus species except $U$. parvum and $U$. urealyticum showed a significantly increasing trend in quantitative detection. The bacterial load of all non-Lactobacillus species increased statistically significantly with the progression from normal to BV microbiota for all species studied except $U$. parvum and $U$. urealyticum. The median bacterial loads for all species were higher for BV than for the normal microbiome except BVAB TM7, Megasphaera type 2, M. curtisii, M. mulieris, and $U$. urealyticum, for which medians for both Nugent I and III were 0. For $U$. parvum and $L$. iners, medians for Nugent I were higher than those for Nugent III.

\section{Associations between age, lifetime number of male sexual partners, STIs and BV}

The median age was the same (24 years) for women with Nugent I flora and women with Nugent III $(\mathrm{p}=0.8)$; no relationship between the lifetime number of male sexual partners and BV could be found.

No statistically significant relationships between individual STIs and BV could be found.

Table 3 Proportion of women in which non-Lactobacillus species were detected

\begin{tabular}{|c|c|c|c|c|c|c|c|c|}
\hline & \multirow{2}{*}{\multicolumn{2}{|c|}{$\begin{array}{c}\text { Nugent I (0-3) } \\
N=73\end{array}$}} & \multirow{2}{*}{\multicolumn{2}{|c|}{$\begin{array}{c}\text { Nugent II (4-6) } \\
N=25\end{array}$}} & \multirow{2}{*}{\multicolumn{2}{|c|}{$\begin{array}{c}\text { Nugent III (7-10) } \\
N^{3}=79\end{array}$}} & \multirow{2}{*}{\multicolumn{2}{|c|}{$\mathrm{p}$-values for trend }} \\
\hline & & & & & & & & \\
\hline & $\begin{array}{c}\text { Qualitative } \\
\text { detection } \\
\text { N (\%) }\end{array}$ & $\begin{array}{c}\text { Quantitative }^{2} \\
\text { detection } \\
\text { N (\%) }\end{array}$ & $\begin{array}{c}\text { Qualitative }^{1} \\
\text { detection } \\
\text { N (\%) }\end{array}$ & $\begin{array}{c}\text { Quantitative }^{2} \\
\text { detection } \\
\text { N (\%) }\end{array}$ & $\begin{array}{c}\text { Qualitative }^{1} \\
\text { detection } \\
\text { N (\%) }\end{array}$ & $\begin{array}{c}\text { Quantitative }^{2} \\
\text { detection } \\
\text { N (\%) }\end{array}$ & $\begin{array}{c}\text { Qualitative } \\
\text { detection } \\
\text { p-value }\end{array}$ & $\begin{array}{c}\text { Quantitative } \\
\text { detection } \\
\text { p-value }\end{array}$ \\
\hline A. vaginae & $55(75)$ & $6(8)$ & $22(88)$ & $13(52)$ & $79(100)$ & $75(95)$ & $<0.0001$ & $<0.0001$ \\
\hline S. sanguinegens & $10(14)$ & $2(3)$ & $9(36)$ & $5(20)$ & $59(75)$ & $53(67)$ & $<0.0001$ & $<0.0001$ \\
\hline L. amnionii & $30(41)$ & $2(3)$ & $15(60)$ & $6(24)$ & $68(86)$ & $63(80)$ & $<0.0001$ & $<0.0001$ \\
\hline BVAB 1 & $23(31)$ & $5(7)$ & $11(44)$ & $6(24)$ & $53(67)$ & $43(54)$ & $<0.0001$ & $<0.0001$ \\
\hline BVAB 2 & $15(21)$ & $2(3)$ & $10(40)$ & $8(32)$ & $72(91)$ & $69(87)$ & $<0.0001$ & $<0.0001$ \\
\hline BVAB 3 & $10(14)$ & $6(8)$ & $11(44)$ & $9(36)$ & $52(66)$ & $52(66)$ & $<0.0001$ & $<0.0001$ \\
\hline BVAB-TM7 & $0(0)$ & $0(0)$ & $6(24)$ & $6(24)$ & $27(34)$ & $27(34)$ & $<0.0001$ & $<0.0001$ \\
\hline Megasphaera type 1 & $30(41)$ & $1(1)$ & $17(68)$ & $9(36)$ & $68(86)$ & $64(81)$ & $<0.0001$ & $<0.0001$ \\
\hline Megasphaera type 2 & $5(7)$ & $0(0)$ & $3(12)$ & $2(8)$ & $25(32)$ & $22(28)$ & $<0.0001$ & $<0.0001$ \\
\hline Eggerthella-like bacterium & $47(64)$ & $3(4)$ & $18(72)$ & $6(24)$ & $75(95)$ & $62(78)$ & $<0.0001$ & $<0.0001$ \\
\hline M. curtisii & $1(1)$ & $1(1)$ & $3(12)$ & $3(12)$ & $20(25)$ & $20(25)$ & $<0.0001$ & $<0.0001$ \\
\hline M. mulieris & $5(7)$ & $1(1)$ & $4(16)$ & $3(12)$ & $16(20)$ & $12(15)$ & 0.018 & 0.003 \\
\hline G. vaginalis & $71(97)$ & $6(8)$ & $24(96)$ & $10(40)$ & $79(100)$ & $69(87)$ & 0.19 & $<0.0001$ \\
\hline M. hominis & $11(15)$ & $3(4)$ & $7(28)$ & $4(16)$ & $50(63)$ & $46(58)$ & $<0.0001$ & $<0.0001$ \\
\hline U. parvum & $37(51)$ & $18(25)$ & $10(40)$ & $5(20)$ & $40(51)$ & $22(28)$ & 0.99 & 0.64 \\
\hline U. urealyticum & $7(10)$ & $4(5)$ & $4(16)$ & $2(8)$ & $14(18)$ & $11(14)$ & 0.15 & 0.08 \\
\hline F. magna & $30(41)$ & $30(41)$ & $17(68)$ & $17(68)$ & $50(63)$ & $50(63)$ & 0.006 & 0.006 \\
\hline Prevotella spp. & $70(96)$ & $3(4)$ & $24(96)$ & $12(48)$ & 77 (97) & $75(95)$ & 0.59 & $<0.0001$ \\
\hline
\end{tabular}

Presence versus absence as determined by the target qPCR.

${ }^{2}$ Presence ( $\geq$ cut-off $/ \mathrm{ml}$ ) versus absence $(<$ cut-off $/ \mathrm{ml}$ ) with cut-off determined by ROC curve analysis.

${ }^{3} \mathrm{~N}$ indicates number of participants. 
Associations between different vaginal bacteria and BV In the qualitative detection, all bacteria were significantly associated with BV except for G. vaginalis, Prevotella spp., $U$. parvum, $U$. urealyticum, and $L$. iners. The strength of association between BV and the bacteria under study increased when odds-ratios were calculated using quantitative detection, i.e., with cut-offs determined by ROC curve analysis (Table 4). For A. vaginae, G. vaginalis, and BVAB TM7, the OR could not be calculated for qualitative detection due to the presence of these bacteria in all women with BV or absence in all women without BV (BVAB TM7). The OR for $L$. iners was 0 in qualitative detection. In quantitative detection, the OR could not be calculated for BVAB TM7 and Megasphaera type 2 due to their absence in women without BV or, in the case of $L$. iners, presence in all women without BV. U. parvum, $U$. urealyticum, and $L$. iners were not associated with BV. With quantitative detection and cut-off determined by ROC, all other bacteria were statistically associated with BV $(\mathrm{p}<0.01)$.

\section{Best prediction of BV in a multivariate logistic regression model}

When analysing the seven bacteria with the largest AUCs (marked with stars in Table 4) in a multivariate logistic regression model, only Prevotella spp. and A. vaginae remained associated with $\mathrm{BV}$, with $\mathrm{p}$-values of 0.0095 and 0.03 and odds ratios of 4.4 and 1.9 , respectively (Table 5), after adjusting for other bacteria.

\section{Vaginal bacterial communities in women with and without BV}

The vaginal bacterial community composition as shown by a clustering tree attached to a heat-map of normalised values of $16 \mathrm{~S}$ rRNA gene copies was diverse and heterogeneous in women with BV. L. iners was the main species detected in women without BV (Figure 1). Among women with BV, three clusters were dominated by single taxa, i.e., Prevotella spp., BVAB1, and G. vaginalis; one cluster was dominated by G. vaginalis/Prevotella spp. while another cluster had BVAB1/G. vaginalis (Figure 1). The remaining BV clusters contained multiple bacterial species. Among the studied bacteria, $L$. iners was the best represented species among women without BV, while Prevotella spp. and G. vaginalis were present in higher proportions than the rest of bacteria were in women with Nugent III.

Co-occurrence of bacterial taxa was investigated by calculating Spearman correlation coefficients (Figure 2, see Additional file 2: Table S2 for a tabulation of the coefficients). The most significant cluster of correlations

Table 4 Odds-ratios (OR) and 95\% confidence intervals (CI) (Fisher's exact test) for BV

\begin{tabular}{|c|c|c|c|c|c|c|}
\hline \multirow[t]{2}{*}{ Species } & \multicolumn{3}{|c|}{ Qualitative detection } & \multicolumn{3}{|c|}{ Quantitative detection } \\
\hline & Observed OR & $95 \% \mathrm{Cl}$ & p-value & Observed OR & $95 \% \mathrm{Cl}$ & p-value \\
\hline Atopobium vaginae & $\infty$ & $6-\infty$ & $<0.0001$ & 209 & $50-985$ & $<0.0001$ \\
\hline Sneathia sanguinegens & 19 & $8-48$ & $<0.0001$ & 72 & $16-634$ & $<0.0001$ \\
\hline Leptotrichia amnionii & 9 & $4-21$ & $<0.0001$ & 140 & $30-1233$ & $<0.0001$ \\
\hline BVAB 1 & 4 & $2-9$ & $<0.0001$ & 16 & $6-56$ & $<0.0001$ \\
\hline BVAB 2 & 40 & $14-120$ & $<0.0001$ & 245 & $49-2191$ & $<0.0001$ \\
\hline BVAB 3 & 12 & $5-30$ & $<0.0001$ & 22 & $8-67$ & $<0.0001$ \\
\hline BVAB-TM7 & $\infty$ & $9-\infty$ & $<0.0001$ & $\infty$ & $9-\infty$ & $<0.0001$ \\
\hline Megasphaera type 1 & 9 & $4-21$ & $<0.0001$ & 307 & $43-12480$ & $<0.0001$ \\
\hline Megasphaera type 2 & 6 & $2-22$ & 0.0002 & $\infty$ & $7-\infty$ & $<0.0001$ \\
\hline Eggerthella-like bacterium & 10 & $3-43$ & $<0.0001$ & 85 & $23-453$ & $<0.0001$ \\
\hline Mobiluncus curtisii & 24 & $4-1025$ & $<0.0001$ & 24 & $4-1025$ & $<0.0001$ \\
\hline Mobiluncus mulieris & 3 & $1-13$ & 0.019 & 13 & $2-559$ & 0.002 \\
\hline Gardnerella vaginalis & $\infty$ & $0.2-\infty$ & 0.229 & 77 & $24-263$ & $<0.0001$ \\
\hline Lactobacillus iners & 0 & $0-2$ & 0.121 & ND & ND & ND \\
\hline Mycoplasma hominis & 10 & $4-23$ & $<0.0001$ & 33 & $9-171$ & $<0.0001$ \\
\hline Ureaplasma parvum & 1 & $0.5-2$ & $>0.9999$ & 1 & $0.5-3$ & 0.7 \\
\hline Ureaplasma urealyticum & 2 & $0.7-6$ & 0.1651 & 3 & $0.7-13$ & 0.104 \\
\hline Finegoldia magna & 2 & $1-5$ & 0.0091 & 2 & $1-5$ & 0.0091 \\
\hline Prevotella spp. & 2 & $0.2-20$ & 0.671 & 437 & $82-2779$ & $<0.0001$ \\
\hline
\end{tabular}

Nugent grade I (73 women) compared to grade III (79 women). Intermediate flora not included. 
Table 5 Adjusted odds ratios with $95 \%$ confidence intervals and $p$-values in a multivariate logistic regression analysis

\begin{tabular}{lccc}
\hline Species & \multicolumn{3}{c}{ Logistic regression model } \\
\cline { 2 - 4 } & Adjusted OR & $\mathbf{9 5 \%} \mathbf{C l}$ & p-value \\
\hline Atopobium vaginae & 1.9 & $1.1-3.6$ & 0.03 \\
Leptotrichia amnionii & 1.1 & $0.6-2.2$ & 0.7 \\
BVAB2 & 2.0 & $0.9-4.4$ & 0.07 \\
Megasphaera type 1 & 1.4 & $0.9-2.4$ & 0.1 \\
Eggerthella-like bacterium & 1.1 & $0.6-2.0$ & 0.6 \\
Gardnerella vaginalis & 1.6 & $0.7-3.9$ & 0.2 \\
Prevotella spp. & 4.4 & $1.4-13.5$ & 0.0095
\end{tabular}

The seven bacterial species were selected by ROC curve analysis with an area under the curve $>85 \%$.

Data are $\log _{10}$ of 165 rRNA gene copies plus one and outcome is BV compared with normal flora as determined by Nugent's score. above 0.5 was found between BVAB2 and A. vaginae, S. sanguinegens, L. amnionii, BVAB3, Megasphaera type 1, and Eggerthella. Strong correlations were also observed for L. amnionii with BVAB2 and 3, Megasphaera type 1, and Eggerthella. Significant interactions were also found for G. vaginalis with A. vaginae and for M. hominis with S. sanguinegens and BVAB3. Negative correlations were found primarily for $L$. iners, which had correlations below -0.5 with $A$. vaginae, Prevotella spp., BVAB2, and G. vaginalis.

\section{Discussion}

We found a high prevalence of BV in women from Greenland, with $45 \%$ of the women scoring positive for BV as determined by Nugent score. These figures are slightly higher than the $38 \%$ found in STD clinic attendees

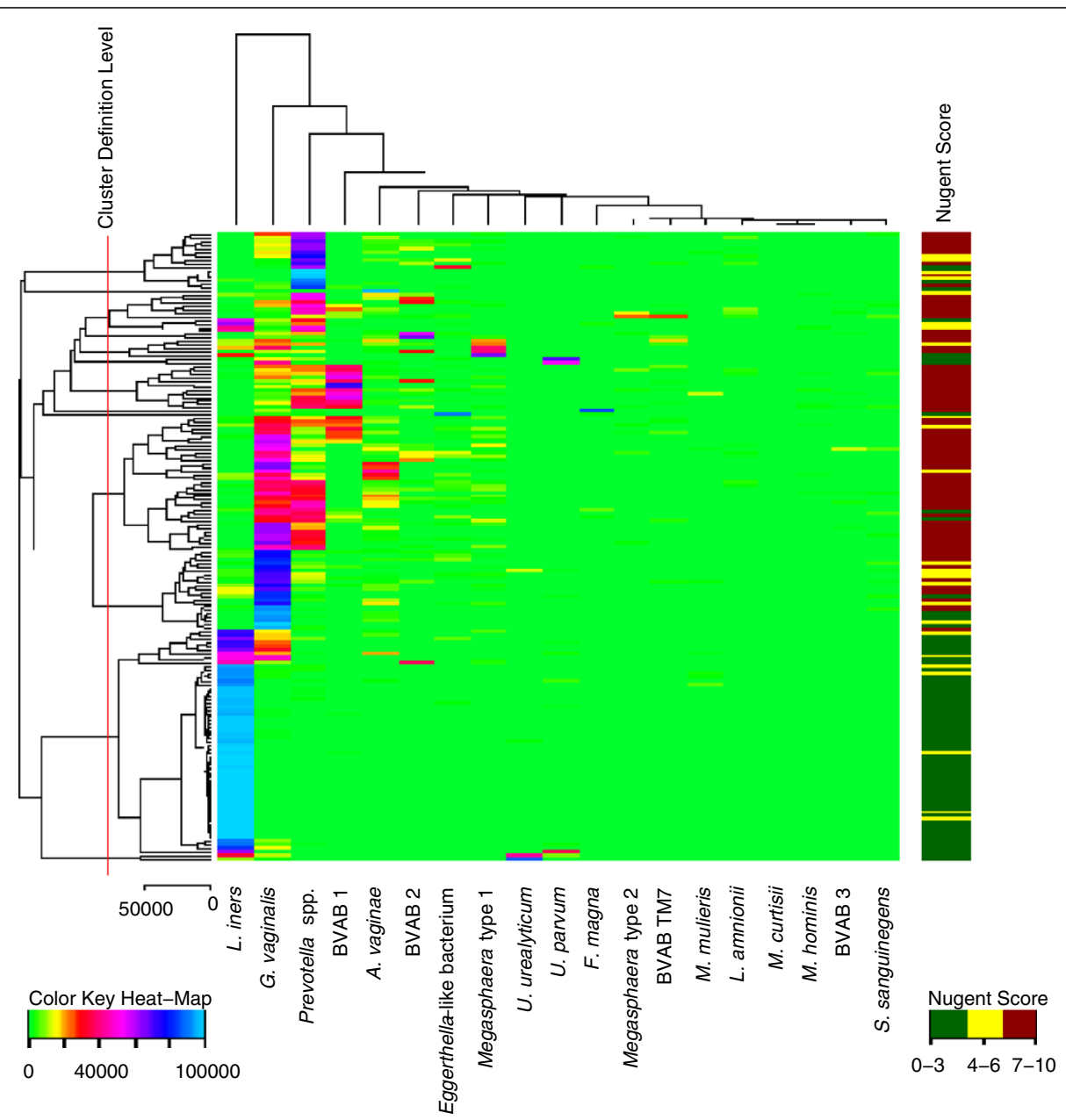

Figure 1 Vaginal bacterial communities. Heat-map constructed by normalising the number of 16S rRNA gene copies/ml UTM for vaginal bacteria in 177 women from Greenland with or without BV. Nugent scores are shown in the vertical column. The scale bar represents the Euclidean distance, corresponds to 50,000 and is calculated after Pythagorean metric. The colour key shows colour code and corresponds to normalised $\mathrm{geq} / \mathrm{ml}$ UTM for each bacterium. The vertical red line indicates the level that was chosen for defining the clusters. 


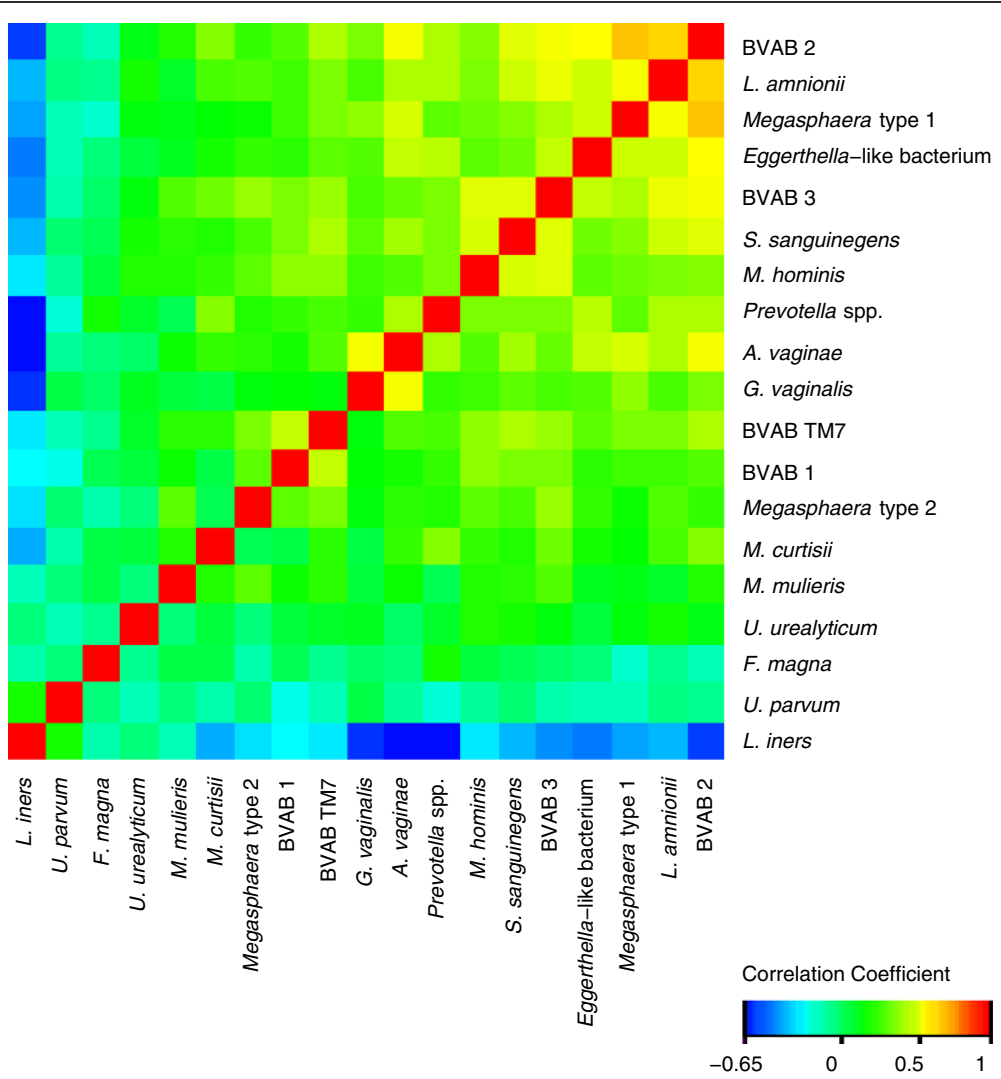

Figure 2 Co-occurrence of bacterial species. Hierarchically clustered Spearman correlation coefficients between bacterial species. Correlation values range from -0.65 to 1. Diagonal elements have a correlation of 1. Several bacteria associated with BV occur together. A tabulation of the coefficients is available in (Additional file 2: Table S2).

in 1991 [18] and comparable with the prevalence of BV in African women [31]. STIs are highly prevalent in Greenland, with chlamydia rates above 5,000/ 100,000 inhabitants. We also found N. gonorrhoeae in $1 \%$, C. trachomatis in $7 \%$, and M. genitalium in $12 \%$ of women tested, but $T$. vaginalis in only one woman (0.5\%). BV has been associated with $C$. trachomatis [32] and N. gonorrhoeae infections [33-35], but we did not find a statistically significant association between any of the STIs and BV.

In contrast to other studies [36,37], no difference in age between women with and without BV could be found. An association between the lifetime number of sexual partners and/or a recent new partner has been found in several studies [14]; however, we did not confirm this association in the present study. Whether this outcome can be explained by the high number of male partners reported by the women in the present study is not clear. The women in this study reported a median of 12.5 partners (Table 1), much higher than the median of four partners reported by women in the UK National Survey of Sexual Attitudes and Lifestyles (NATSAL2000) [38]. Thus, it is possible that the effect of the number of partners was already saturated in the current study's population.

L. iners was detected by PCR in every participant with normal flora at a median concentration as high as $3 \times$ $10^{6} 16 \mathrm{~S}$ rRNA copies/ml UTM, a value higher than in women with BV (median $8 \times 10^{5} 16 \mathrm{~S} \mathrm{rRNA}$ copies $/ \mathrm{ml}$ ). This finding is in accordance with other studies that suggest $L$. iners is present in the majority of women regardless of BV status [27]. Unfortunately, our DNA extraction method did not allow for reproducible quantitative detection of other Lactobacillus spp., and the amount of the original specimen did not allow for a repeated extraction. The incomplete lysis of Lactobacillus spp. other than $L$. iners was confirmed in an experiment comparing the Chelex extraction used in this study with a modified QIAamp extraction protocol that included a preincubation step with lysozyme on clinical specimens collected independently from the present study. L. iners was detected with good agreement between the two methods, but 11 of $12 \mathrm{~L}$. gasseri positive specimens showed false negatives after Chelex extraction. Therefore, only L. iners qPCR was performed on the samples in this study, and consequently, we could not classify the flora according to 
community groups, as previously described by Ravel et al. [10].

In the present study, we showed that PCR may be a useful tool in diagnosing BV. However, we found that most of the BV-associated bacteria were also present in women without $\mathrm{BV}$, and therefore, qualitative detection could not be used for diagnostic purposes. Consequently, we used quantitative data obtained by applying ROC curve analysis to determine the optimal cut-off level for diagnostic purposes. It was found that seven species $(A, v a-$ ginae, Prevotella spp., G. vaginalis, BVAB2, Eggerthella-like bacterium, L. amnionii, and Megasphaera type 1) showed promising diagnostic potential in that they had areas under the ROC curve of $>85 \%$, which suggests good discriminatory power for BV prediction. Some of these species, i.e., A. vaginae, G. vaginalis, BVAB2, and Megasphaera type 1, have been previously reported to be useful predictors for BV $[39,40]$. The same set of qPCRs applied on vaginal swabs from a Swedish population revealed the same seven bacterial species as the best predictors for BV [41]. However, the thresholds for bacterial load in our study were not identical to the study by Shipitsyna. This discrepancy can be explained to some extent by the use of different methods for diagnosing BV (Nugent in the present study in contrast to Amsel's criteria in the study by Shipitsyna), different DNA extraction methods (simple lysis by boiling with Chelex resin versus a Qiagen DNeasy Blood and Tissue Kit), and different methods of collecting the samples (self-collected with flocked swabs in UTM versus physician collected samples with $10 \mu \mathrm{l}$ plastic loops). For most species, the threshold values in the present study were 10- to 50-fold higher than those found in the Swedish patients. However, some notable differences were observed; BVAB3 had a 7-fold lower threshold in the women from Greenland, while Eggerthella-like bacterium, BVAB1, and Mobiluncus mulieris had thresholds approximately 2000fold higher in the women from Greenland, suggesting a much higher level of carriage in women without BV as determined by Nugent score. Whether these differences reflect true population differences or can be traced back to technical differences remains unclear, but these results emphasise that relevant thresholds should be determined in the population under study using standardised techniques. The vaginal swab specimens were kept in Copan UTM transport medium and refrigerated for up to 5 days before shipment at ambient temperature, typically reaching the laboratory within 1 to 2 days. It cannot be excluded that some growth or even degradation of microbial DNA may have occurred during this time and led to the differences in threshold values. However, the UTM medium contains colistin, vancomycin, and amphotericin B, which restrict the growth of Gram-positive bacteria, Gram-negative bacteria, and fungi, respectively, and because many of the BV-associated bacteria have been excessively difficult to cultivate, distortion of the microflora during transport is most likely insignificant. Furthermore, in another study (Datcu et al., accepted for publication), the bacterial load of eight selected BV associated bacteria in first void urine samples transported in GeneLock (a transport medium designed to stabilise DNA and RNA) was shown to correlate significantly with the bacterial load in the corresponding vaginal swab specimens described in the present study, suggesting that degradation of DNA in UTM during transport is not of major importance.

Using quantitative detection and Nugent scoring as the gold standard for BV, the combination of Prevotella spp. and A. vaginae had a high specificity at $99 \%$, but the sensitivity decreased to $90 \%$. When considering Prevotella spp. or A. vaginae, the specificity decreased to $89 \%$ while the sensitivity increased to $100 \%$. Thus, by combining "Prevotella spp. and/or A. vaginae," it is possible to select either an almost perfect specificity or an optimal sensitivity. Consequently, these 2 real-time PCRs together can diagnose BV with extremely high accuracy.

The average number of non-Lactobacillus species represented in the samples, i.e., the diversity, increased with progression from the normal microbiome (average 6.2 species with a range of 3-10) to BV (average 11.7 species, range 5-16). Fredricks et al. [27] found an average of only 3.6 species (range $0-14$ ) detected in women without BV, a difference that could be explained partly because PCR assays for $M$. hominis, $U$. urealyticum, and U. parvum were not performed and one PCR assay was used for both Leptotrichia/Sneathia spp. Compared with data presented for the vaginal flora of US women [27], the flora in women from Greenland was different largely in the detection of nearly all evaluated species in a markedly higher proportion of the women from Greenland with normal microbiota as determined by Nugent's criteria. However, Zozaya-Hinchliffe [29] found an average of 9.5 non-Lactobacillus species for women with normal vaginal flora in samples from US women who attended an STD clinic. Whether this increase reflects differences in the detection limit of the assays or a higher rate of colonisation with these bacteria due to either behavioral or genetic differences remains to be established. The women included in the present study had a high number of lifetime sexual partners, and a previous study by Fethers and colleagues [42] showed that increasing frequency of six of the eight BV candidate organisms included in the study (Megasphaera type 1, BVAB 2, BVAB 3, Sneathia spp., Leptotrichia spp., and G. vaginalis) correlated with increasing sexual exposure, suggesting potential sexual transmission of these bacteria.

Using quantitative detection with cut-offs determined by ROC analysis, all non-Lactobacillus species except $U$. parvum and $U$. urealyticum were significantly associated with BV in univariate analysis. Prevotella spp. 
and $A$. vaginae remained significantly associated with BV in a multivariate logistic regression model performed on the seven species selected by their AUC values of $>85 \%$ in ROC analysis.

The women with Nugent grade III could be further divided into distinct sub-types of BV flora dominated by different bacterial species, such as Prevotella spp., G. vaginalis, or BVAB 1, or by combinations of species, dominated by G. vaginalis/Prevotella spp. and BVAB1/ G. vaginalis. This finding is in accordance to some extent with other studies using 454 pyrosequencing of amplicons generated with universal $16 \mathrm{~S}$ primers [43], although the clusters identified in the present study were somewhat different, particularly with Sneathia/Leptotrichia spp.-dominated clusters being less prominent. Whether this difference reflects methodological or true populationdependent differences is not clear. The sub-clustering clearly suggests that the diagnosis of BV may be a simplified grouping of several conditions and refined diagnostic methods may prove useful in both stratifying the treatment of the condition and targeting treatment to prevent complications in relevant subgroups.

Prevotella spp. have been found in the majority of patients in culture-based surveys of vaginal microbiomes [44] and are one of the most common operational taxonomic units (OTUs) present in recent molecular studies [45]. Prevotella spp. and BVAB1 have been reported to dominate in single taxon clusters of BV communities [43]. Bacteria that dominate in pairs may act synergistically or may have a symbiotic or even mutual relationship; this may be the case for G. vaginalis with Prevotella spp.; it has been shown that amino acids produced during $G$. vaginalis growth may promote the growth of $P$. bivia. Conversely, the growth of $G$. vaginalis becomes limited by a shortage in available ammonia, which can be provided by $P$. bivia [46]. However, we and others have found that G. vaginalis dominated in BV clusters by itself, in the absence of high concentrations of Prevotella spp., suggesting that there may be other mechanisms not clearly understood to sustain the growth of this bacterium.

Correlations between species were also found. Most notably, BVAB2 had strong correlations with A. vaginae, S. sanguinegens, L. amnionii, BVAB3, Megasphaera type 1, and Eggerthella-like bacteria. This is in agreement with findings using 454 pyrosequencing [43], although this study found positive correlations with some Prevotella species but negative correlations with others. However, the less discriminative approach chosen in the present study can easily explain this discrepancy.

The lack of specific detection of other Lactobacillus spp. reported to be part of the normal microbiome of the human vagina, such as Lactobacillus crispatus, Lactobacillus jensenii, and Lactobacillus gasseri, is a potential limitation of the study presented here. However, as these species are mainly associated with healthy vaginal flora, the conclusions reached for women with BV should not be affected. Although using specific quantitative PCRs limits the study to selected species, a major strength of this approach is that individually performed assays are less susceptible to amplification bias. In broad-range 16S PCR, differences in the amplification efficiency resulting from imperfect sequence matches of the primers with some species as well as competitive amplification in which the most abundant species tend to dominate may skew the species distribution. Future research should determine which subtypes of BV communities confer significant health risks to women and aim to stratify treatment to avoid the common recurrence of $\mathrm{BV}$.

\section{Conclusions}

In summary, our study confirmed a high prevalence of $\mathrm{BV}$ in women from Greenland. A. vaginae and G. vaginalis were present in all patients with BV by qualitative detection and also in a high proportion of women with normal microbiota as determined by Nugent's criteria. Using cutoffs determined by ROC curve analysis and a combination of Prevotella spp. and/or A. vaginae PCR, we were able to diagnose BV with high accuracy. Prevotella spp. had the highest odds-ratio and adjusted odds-ratio for BV in univariate analysis. In multivariate logistic analysis, Prevotella spp. and $A$. vaginae were both independently associated with BV. Different clusters of BV communities could be identified in women from Greenland, some of which were dominated by one or two bacterial species, suggesting metabolic co-dependencies. Further molecular studies are needed to establish the clinical consequences of the different BV profiles.

\section{Additional files}

Additional file 1: Table S1. PCR primers and probes with corresponding product sizes, annealing temperatures, and $\mathrm{Mg}^{++}$concentrations.

Additional file 2: Table S2. Spearman correlation coefficients among bacterial species in swabs showing co-occurrence of species.

\section{Competing interests}

The authors declared that they have no competing interests.

\section{Authors' contributions}

Conceived and designed the experiments: JSJ, PA, RD, DG, ER. Performed the experiments: RD. Analysed the data: RD, JSJ, PA. Contributed reagents/ materials/analysis tools: JSJ, PA, RD, DG, GM, RMA, ER, AK. Wrote the manuscript: RD, PA, JSJ. All authors read and approved the final version of the manuscript.

\section{Acknowledgements}

Maria Frølund is thanked for developing the F. magna, BVAB3 and G. vaginalis real-time assays used in the present study. Birthe Dohn, Anemone Ojala and Susanne Cramer Larsson are thanked for excellent technical assistance. 


\section{Author details}

'Microbiology and Infection Control, STI, Research and Development, Statens Serum Institut, Artillerivej 5, DK 2300 Copenhagen S, Denmark. ${ }^{2}$ Dalla Lana School of Public Health, University of Toronto, Toronto, Ontario, Canada. ${ }^{3}$ Centre for Primary Care, Nuuk, Greenland. ${ }^{4}$ University of Greenland, Nuuk, Greenland. ${ }^{5}$ Montana State University, Bozeman, Montana, USA. ${ }^{6}$ Statens Serum Institut, Copenhagen, Denmark.

Received: 2 July 2013 Accepted: 10 October 2013

Published: 16 October 2013

\section{References}

1. Donders G: Diagnosis and management of bacterial vaginosis and other types of abnormal vaginal bacterial flora: a review. Obstet Gynecol Surv 2010, 65:462-473.

2. Lamont RF, Morgan DJ, Wilden SD, Taylor-Robinson D: Prevalence of bacterial vaginosis in women attending one of three general practices for routine cervical cytology. Int J STD AIDS 2000, 11:495-498.

3. Amsel R, Totten PA, Spiegel CA, Chen KC, Eschenbach D, Holmes KK: Nonspecific vaginitis. Diagnostic criteria and microbial and epidemiologic associations. Am J Med 1983, 74:14-22.

4. Nugent RP, Krohn MA, Hillier SL: Reliability of diagnosing bacterial vaginosis is improved by a standardized method of gram stain interpretation. J Clin Microbiol 1991, 29:297-301.

5. Verhelst R, Verstraelen H, Claeys G, Verschraegen G, Van Simaey L, De Ganck C, et al: Comparison between gram stain and culture for the characterization of vaginal microflora: definition of a distinct grade that resembles grade I microflora and revised categorization of grade I microflora. BMC Microbiol 2005, 5:5-61.

6. Ison CA, Hay PE: Validation of a simplified grading of gram stained vaginal smears for use in genitourinary medicine clinics. Sex Transm Infect 2002, 78:413-415.

7. Verstraelen H, Verhelst R, Roelens K, Claeys G, Weyers S, De Backer E, et al: Modified classification of Gram-stained vaginal smears to predict spontaneous preterm birth: a prospective cohort study. Am J Obstet Gynecol 2007, 196:528-529

8. Josey WE, Schwebke JR: The polymicrobial hypothesis of bacteria vaginosis causation: a reassessment. Int J STD AIDS 2008, 19:152-154

9. Allsworth JE, Peipert JF: Prevalence of bacterial vaginosis: 2001-2004 national health and nutrition examination survey data. Obstet Gynecol 2007, 109:114-120

10. Ravel J, Gajer P, Abdo Z, Schneider GM, Koenig SS, McCulle SL, et al: Vaginal microbiome of reproductive-age women. Proc Natl Acad Sci USA 2011 108(Suppl 1):4680-4687.

11. Catlin BW: Gardnerella vaginalis: characteristics, clinical considerations, and controversies. Clin Microbiol Rev 1992, 5:213-237.

12. Dawson SG, Ison CA, Csonka G, Easmon CS: Male carriage of Gardnerella vaginalis. Br J Vener Dis 1982, 58:243-245.

13. Fethers KA, Fairley CK, Morton A, Hocking JS, Hopkins C, Kennedy $\sqcup$, et al: Early sexual experiences and risk factors for bacterial vaginosis. I Infect Dis 2009, 200:1662-1670.

14. Fethers KA, Fairley CK. Hocking JS, Gurrin LC, Bradshaw CS. Sexual risk factors and bacterial vaginosis: a systematic review and meta-analysis. Clin Infect Dis 2008, 47:1426-1435.

15. Verstraelen $H$, Verhelst $R$, Vaneechoutte $M$, Temmerman M: The epidemiology of bacterial vaginosis in relation to sexual behaviour. BMC Infect Dis 2010, 10:81

16. Gesink D, Rink E, Mulvad G, Koch A: Sexual health and sexually transmitted infections in the North American Arctic. Emerg Infect Dis 2008, 14:4-9.

17. Gesink DC, Mulvad G, Montgomery-Andersen R, Poppel U, Montgomery-Andersen S, Binzer A, et al: Mycoplasma genitalium presence, resistance and epidemiology in Greenland. Int I Circumpolar Health 2012, 71:1-8.

18. Moller BR, From E, Christensen RB, Heilmann B, Jensen KE, Thorsen P. The venereological profile in Godthab district venereal clinic, Nuuk, Gronland. A 3-month study in 1991. Ugeskr Laeger 1992, 154:1505-1508.

19. Gesink D, Rink E, Montgomery-Andersen R, Mulvad G, Koch A: Developing a culturally competent and socially relevant sexual health survey with an urban Arctic community. Int J Circumpolar Health 2010, 69:25-37.
20. Rink E, Gesink LD, Montgomery-Andersen R, Mulvad G, Koch A: The practical application of community-based participatory research in Greenland: initial experiences of the Greenland sexual health study. Int $J$ Circumpolar Health 2009, 68:405-413.

21. Jensen JS, Bjornelius E, Dohn B, Lidbrink P: Use of TaqMan 5' nuclease real-time PCR for quantitative detection of Mycoplasma genitalium DNA in males with and without urethritis who were attendees at a sexually transmitted disease clinic. J Clin Microbiol 2004, 42:683-692.

22. De Backer E, Verhelst R, Verstraelen H, Alqumber MA, Burton JP, Tagg JR: Quantitative determination by real-time PCR of four vaginal Lactobacillus species, Gardnerella vaginalis and Atopobium vaginae indicates an inverse relationship between L. gasseri and L. iners. BMC Microbiol 2007, 7:115.

23. Jensen JS, Borre MB, Dohn B: Detection of Mycoplasma genitalium by PCR amplification of the 16S rRNA gene. J Clin Microbiol 2003, 41:261-266.

24. Westh $\mathrm{H}$, Jensen JS: Low prevalence of the new variant of Chlamydia trachomatis in Denmark. Sex Transm Infect 2008, 84:546-547.

25. Hjelmevoll SO, Olsen ME, Sollid JU, Haaheim H, Unemo M, Skogen V: A fast real-time polymerase chain reaction method for sensitive and specific detection of the Neisseria gonorrhoeae porA pseudogene. J Mol Diagn 2006, 8:574-581

26. Kengne P, Veas F, Vidal N, Rey JL, Cuny G: Trichomonas vaginalis: repeated DNA target for highly sensitive and specific polymerase chain reaction diagnosis. Cell Mol Biol 1994, 40:819-831.

27. Fredricks DN, Fiedler TL, Thomas KK, Oakley BB, Marrazzo JM: Targeted PCR for detection of vaginal bacteria associated with bacterial vaginosis. J Clin Microbiol 2007, 45:3270-3276.

28. Fredricks DN, Fiedler TL, Thomas KK, Mitchell CM, Marrazzo JM: Changes in vaginal bacterial concentrations with intravaginal metronidazole therapy for bacterial vaginosis as assessed by quantitative PCR. J Clin Microbiol 2009, 47:721-726.

29. Zozaya-Hinchliffe $M$, Lillis $R$, Martin DH, Ferris MJ: Quantitative PCR assessments of bacterial species in women with and without bacterial vaginosis. J Clin Microbiol 2010, 48:1812-1819.

30. Prince AM, Andrus L: PCR - How to kill unwanted DNA. Biotechniques 1992 , 12:358.

31. Bukusi EA, Cohen CR, Meier AS, Waiyaki PG, Nguti R, Njeri JN, et al: Bacterial vaginosis: risk factors among Kenyan women and their male partners. Sex Transm Dis 2006, 33:361-367.

32. Hillier SL, Krohn MA, Klebanoff SJ, Eschenbach DA: The relationship of hydrogen peroxide-producing lactobacilli to bacterial vaginosis and genital microflora in pregnant women. Obstet Gynecol 1992, 79:369-373.

33. Das S, Allan S: Higher vaginal $\mathrm{pH}$ is associated with Neisseria gonorrhoeae and Chlamydia trachomatis infection in a predominantly white population. Sex Transm Dis 2006, 33:527-528.

34. Das S, Sabin C, Allan S: Higher vaginal pH is associated with Chlamydia trachomatis infection in women: a prospective case-controlled study. Int J STD AIDS 2005, 16:290-293.

35. Wiesenfeld HC, Hillier SL, Krohn MA, Landers DV, Sweet RL: Bacterial vaginosis is a strong predictor of Neisseria gonorrhoeae and Chlamydia trachomatis infection. Clin Infect Dis 2003, 36:663-668.

36. Moi H: Prevalence of bacterial vaginosis and its association with genital infections, inflammation, and contraceptive methods in women attending sexually transmitted disease and primary health clinics. Int J STD AIDS 1990, 1:86-94.

37. Desseauve D, Chantrel J, Fruchart A, Khoshnood B, Brabant G, Ancel PY, et al: Prevalence and risk factors of bacterial vaginosis during the first trimester of pregnancy in a large French population-based study. Eur J Obstet Gynecol Reprod Biol 2012, 163:30-34

38. Johnson AM, Mercer CH, Erens B, Copas AJ, McManus S, Wellings $\mathrm{K}$, et al: Sexual behaviour in Britain: partnerships, practices, and HIV risk behaviours. Lancet 2001, 358:1835-1842.

39. Menard JP, Fenollar F, Henry M, Bretelle F, Raoult D: Molecular quantification of Gardnerella vaginalis and Atopobium vaginae loads to predict bacterial vaginosis. Clin Infect Dis 2008, 47:33-43.

40. Cartwright CP, Lembke BD, Ramachandran K, Body BA, Nye MB, Rivers CA, et al: Development and validation of a semiquantitative, multitarget $\mathrm{PCR}$ assay for diagnosis of bacterial vaginosis. J Clin Microbiol 2012, 50:2321-2329.

41. Shipitsyna E, Roos A, Datcu R, Hallen A, Fredlund H, Jensen JS, et al: Composition of the vaginal microbiota in women of reproductive age sensitive and specific molecular diagnosis of bacterial vaginosis is possible? PLOS ONE 2013, 8:e60670. 
42. Fethers K, Twin J, Fairley CK, Fowkes FJ, Garland SM, Fehler G, et al: Bacterial vaginosis (BV) candidate bacteria: associations with $\mathrm{BV}$ and behavioural practices in sexually-experienced and inexperienced women. PLoS One 2012, 7:e30633.

43. Srinivasan S, Hoffman NG, Morgan MT, Matsen FA, Fiedler TL, Hall RW, et al: Bacterial communities in women with bacterial vaginosis: high resolution phylogenetic analyses reveal relationships of microbiota to clinical criteria. PLoS One 2012, 7:e37818.

44. Hillier SL, Krohn MA, Rabe LK, Klebanoff SJ, Eschenbach DA: The normal vaginal flora, $\mathrm{H}_{2} \mathrm{O}_{2}$-producing lactobacilli, and bacterial vaginosis in pregnant women. Clin Infect Dis 1993, 16(Suppl 4):S273-S281.

45. Spear GT, Sikaroodi M, Zariffard MR, Landay AL, French AL, Gillevet PM: Comparison of the diversity of the vaginal microbiota in HIV-infected and HIV-uninfected women with or without bacterial vaginosis. J Infect Dis 2008, 198:1131-1140.

46. Pybus V, Onderdonk AB: Evidence for a commensal, symbiotic relationship between Gardnerella vaginalis and Prevotella bivia involving ammonia: potential significance for bacterial vaginosis. J Infect Dis 1997, 175:406-413.

doi:10.1186/1471-2334-13-480

Cite this article as: Datcu et al:: Vaginal microbiome in women from Greenland assessed by microscopy and quantitative PCR. BMC Infectious Diseases 2013 13:480.

\section{Submit your next manuscript to BioMed Central and take full advantage of:}

- Convenient online submission

- Thorough peer review

- No space constraints or color figure charges

- Immediate publication on acceptance

- Inclusion in PubMed, CAS, Scopus and Google Scholar

- Research which is freely available for redistribution 